
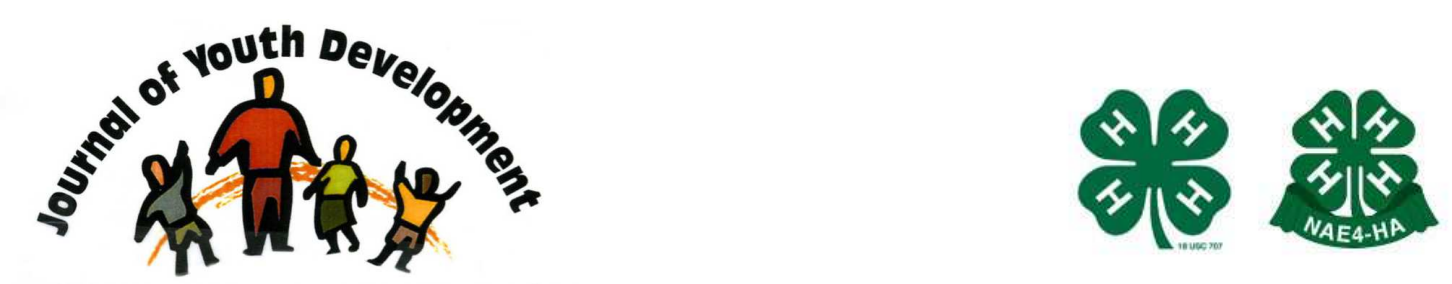

Bridging Research \& Practice

\title{
Organizational Supports and Youth Life Skill Development: Adult Volunteers as Mentors, Managers and "Mediators"
}

\author{
Kate Fogarty \\ Family, Youth \& Community Sciences \\ University of Florida \\ Gainesville, FL \\ kfogarty@ufl.edu \\ Bryan Terry \\ Family, Youth \& Community Sciences \\ University of Florida \\ Gainesville, FL \\ terrys1@ufl.edu \\ Dale Pracht \\ Family, Youth \& Community Sciences \\ University of Florida \\ Gainesville, FL \\ dpracht@ufl.edu \\ Joy Jordan \\ Family, Youth \& Community Sciences \\ University of Florida \\ Gainesville, FL \\ jcj@ufl.edu
}




\title{
JOURNAL OF YOUTH DEVELOPMENT \\ bridging research and practice



Volume 4, Number 4, Winter 2009

Article 090404FA002

\section{Organizational Supports and Youth Life Skill Development: Adult Volunteers as Mentors, Managers and "Mediators"}

\author{
Kate Fogarty, Bryan Terry, Dale Pracht and Joy Jordan \\ University of Florida
}

\begin{abstract}
A statewide community club evaluation (youth self-report), empirically testing a logic model of factors influencing youth life skill development is described. Results supported that the way adult volunteers manage and mentor youth and explained how 4-H program features (e.g., youth sense of belonging, safety, and support) influence life skill development.

Youth engagement in activities was also linked with life skills and organizational supports were linked with youth engagement in the model. Future directions based on the findings to be discussed include: (1) examining volunteer competencies to build upon in training; (2) use of SEM to understand the larger picture of youth programs; and (3) what the results tell us about: (a) creating quality club environments for youth; (b) providing youth with caring adult support systems; and (c) developing life and career skills through subject-matter topics.
\end{abstract}

\section{Introduction}

Positive youth development (PYD) is a broadly based term that encompasses youth resilience and competency-based outcomes. It is fostered by bolstering the developmental assets of youth from a variety of ecological levels (Search Institute, 2004) and engaging youth in productive activities rather than correcting negative behavior (Damon, 2004). PYD is manifested into adaptive functioning including the acquisition of life skills and competencies for adult life. Over the past decade, studies have shown that youth spending time in engaging, safe, structured, adult-supervised, and health promoting activities, i.e., non-formal educational settings such as community clubs and afterschool programs, attain a variety of competencies and life skills and are less likely to become involved in health risk behaviors (Dierking \& Faulk, 2003; Eccles \& Gootman, 2002; Roth et al., 1998). 
Learning environments that promote positive youth development, developmental assets, and life skill development have notable features. Eccles \& Gootman (2002) identified eight features for ideal community-based settings for youth:

(1) physical and psychological safety;

(2) supportive relationships;

(3) appropriate structures;

(4) opportunities to belong;

(5) positive social norms;

(6) support for efficacy and mattering;

(7) connections among youth environments (e.g., family, school, \& community); and

(8) life skill development.

Simplified, these learning environments provide learning opportunities and a safe, supportive environment (contextual influences) that facilitate life skills (youth outcomes). However, associations among these features of youth development organizations and educational delivery systems remain largely unexplored.

Youth-serving community-based clubs provide one example of long-term positive learning environments for youth in non-formal educational settings. Community-based clubs, facilitated and structured by adult volunteers yyouth program staff, are ideal high context learning environments for youth to build life skill competencies and enhance assets at the individual, family, and community levels. For example, fifth through twelfth grade students who participated in community-based clubs for one or more years had higher or increased: educational aspirations; achievement motivation; intentions to help others; self-esteem; levels of interaction and communication with adults; decision-making skills; and ability to make friends (Rodriguez, Hirschl, Mead, \& Goggin, 1999).

Community-based clubs, provided they maximize their use of volunteer and staff expertise and tested curricula, have noteworthy association with life skill development. Among the gamut of educational programs or delivery systems available to youth, community clubs represent a paramount means of fostering positive development. As compared with summer day camps or after school programs, community clubs are characterized by long-term, high-context and high content educational delivery for youth (Kress, 2007). High-context denotes the contextual nature of learning that takes place on-site within community clubs. Community mapping projects for youth, civic engagement activities (Lerner, 2004), and experientially-based learning of relevant life skills like workforce preparation are examples of high-context educational delivery. Content refers to subject matter areas of expertise, curricula content, and life skills capacities promoted (Kress, 2007), in which community clubs have great potential to influence youth life skill development.

Volunteers contribute to community clubs by carrying out many roles and fill positions that both directly and indirectly affect youth (Boyce, 1971). This includes:

(1) supporting youth in the achievement of their goals;

(2) providing learning opportunities that interest youth in a community club; and

(3) Creating safe and secure environments for youth. 
The ability of programs to provide safe and secure environments for youth depends upon the involvement and quality of adult staff and volunteers. Supportive relationships happen when young people and adults become engaged together in their communities; they are relationships between youth and adults where there is mutuality in teaching, learning, and action (Zeldin, McDaniel, Topitzes \& Lorens, 2001). Mutuality is what distinguishes supportive relationships from parent-child, student-teacher, or mentoring relationships (Camino, 2000). Supportive relationships focus on nurturance; they emphasize youth and their contributions rather than problems. Positive expectations for behavior refer to shared beliefs or expectations in a social group about how people in general or members of the group ought to behave to promote healthy youth behaviors and decrease the chance that youth will engage in risky behaviors (Christensen, Rothgerber, Wood, \& Matz, 2004).

Volunteers serve as role models and mentors, providing social support to the youth they serve. A mentor:

1) has greater experience or wisdom than the mentee;

2) offers guidance or instruction that is intended to facilitate the growth and development of the mentee; and

3) facilitates the development of an emotional bond and trust with the mentee (Freedman 1992).

In other words, volunteer educators (mentors) provide critical guidance to engage youth experientially while supporting and validating learning from these experiences. Mentors have been found to positively influence youth (Dubois, Halloway, Valentine, \& Cooper, 2002; Rhodes, 2002). However, research on the process of mentoring is limited and is needed to gain a deeper understanding of the mentoring relationships that may account for youth outcomes (DuBois \& Karcher, 2005).

\section{Purpose}

Community-based clubs for youth, characterized by high-context and high educational content, in out-of-school settings rely largely on a volunteer corps for program delivery. While families and schools have the greatest influence on youth development, personal development that must occur and the skills and competencies that youth achieve depend upon the resources of the broader community in these out-of-school settings (Blyth, 1992; Carnegie Corporation of New York, 1992; Lerner, 1995; Schorr, 1989).

Volunteers help to serve and represent community-based organizations in meeting the needs of their constituents (Borden \& Perkins, 2007); in other words, volunteer influence potentially mediates the relation between program features and youth life skill outcomes. The evaluation of youth programs is largely based on a direct main-effect approach between youth program features and youth outcomes. Less attention has been given to examining underlying mechanisms to explain the direct effects of structural or program features on youth outcomes. Some, however, have proposed (cf., MacKinnon \& Dwyer, 1993) and found support for effective youth intervention that targets mediators in order to influence positive program outcomes (cf. Stice, Presnell, Gau \& Shaw, 2007).

This study empirically examined the mediating influence of volunteer support on the relationship between contextual influences (e.g., organizational features and youth education experiences) and life skill outcomes. In other words, the question becomes, do volunteer 
influences explain the link between contextual features of nonformal youth education and youth outcomes?

The following hypotheses were tested in the study:

(1) learning opportunities provided by community-based clubs relate positively with support provided by volunteers;

(2) supportive environments provided by community-based clubs relate positively with support provided by volunteers;

(3) learning opportunities and supportive environments have a positive relationship with youth outcomes; and

(4) volunteer support mediates the relationship among learning opportunities and supportive environments and youth outcomes.

The overall aim of the 4-H club evaluation was to illustrate how selected factors (volunteer support systems, youth engagement in activities, and environmental and organizational supports) fall into a conceptual model in their associations with life skill outcomes. This conceptual model can:

(1) aid our understanding about how program features work to influence life skill outcomes;

(2) guide youth development professionals toward focus areas to more effectively influence youth life skills; and

(3) point to new directions in evaluation, for example, examining how specific volunteer competencies (and areas to target in volunteer training) might explain program feature effects on youth life skills.

\section{Method}

A community-based club evaluation survey was completed by over 600 youth from 44 countybased locations in a Southeastern state in the summer and fall of 2005. In accordance with approved institutional review board protocol for human subjects at the land grant institution, a cover letter and instructions were provided by a county extension youth development educator to each community club leader and parent describing the confidentiality, process, distribution, and voluntary nature of the survey.

Community club leaders distributed questionnaires to each youth member enrolled in a community club. Upon completion, the questionnaires were collected by the community club leader and county extension youth development educator and then forwarded to the authors of the study for data entry and analysis. Respondent youth came from approximately equal proportions of urban/suburban (49.7\%) and rural counties (50.0\%). Of the 628 respondents, $64.3 \%$ were female, the average age was 12.9 years old, $68.0 \%$ were from rural or small towns, and $70.6 \%$ were Caucasian. See Table 1 for participant information. 
Table 1

Description of Youth Participants in Life Skills Outcome Study ( $N=628)$

\begin{tabular}{|l|r|l|}
\hline $\begin{array}{l}\text { Mean Age } \\
\text { 12.96 years (SD=2.83) }\end{array}$ & Number & Percentage \\
\hline Sex & & \\
$\quad$ Male & 208 & $35.7 \%$ \\
$\quad$ Female & 374 & $64.3 \%$ \\
$\quad$ Missing) & 46 & \\
\hline Ethnicity & & \\
Caucasian & 445 & $70.6 \%$ \\
African-American & 15 & $2.4 \%$ \\
Hispanic & 32 & $5.1 \%$ \\
Asian & 3 & $.5 \%$ \\
Other & 69 & $12.2 \%$ \\
(Missing) & 64 & \\
\hline Residence & & \\
Rural & 237 & $41.4 \%$ \\
Small Town & 152 & $26.6 \%$ \\
Urban Area & 183 & $32.0 \%$ \\
(Missing) & 56 & \\
\hline
\end{tabular}

A retrospective design was used in administering the survey and collecting data in a crosssectional, non-experimental study. The survey was designed to assess perceptions of organizational and environmental support by youth recipients and adult volunteers, as well as life skill gains among youth. The survey instrument utilized in this study was adapted from a 2004 impact study of a nonformal youth education program in Nevada (cf., Singletary \& Smith, 2004). The survey included multiple questions to measure learning opportunities, supportive environments, volunteer support, and youth outcomes. Response options ranged from ' $1=$ Not at All' to ' $5=$ All the Time.'

Once data were collected and entered into a database, preliminary examinations were conducted to discern factors among positive youth outcomes (life skill gains) and "predictors" that are associated with positive youth outcomes. Principal components exploratory factor analysis (EFA), using varimax and oblimin rotations as alternatives to a non-rotated solution, of items indicating organizational supports, produced three factors that explained the majority of inter-item variance:

(1) volunteer support system;

(2) youth engagement in activities; and

(3) environmental and organizational supports.

A composite latent life skills variable reflected a variety of life skill types including: general mastery; decision-making skills; and self-responsibility.

The aim of the following research was to illustrate how the above factors fall into a conceptual model in their associations with life skills outcomes. It was expected that contextual influences (learning opportunities, and supportive organizational environments) influence or associate with youth life skills by way of volunteer support systems. In other words, because volunteers and staff represent youth organizations and work in close proximity with youth, we wanted to know: 
to what extent do volunteers bridge the relation between contextual/organizational environments and youth life skill outcomes?

The model of interest examined how organizational supports related to life skills as a positive youth development outcome. A mediator model was utilized to test the conceptual framework of this study. Simply stated, a mediator is an influence that accounts for the relation between two variables, a predictor and outcome (Baron \& Kenny, 1986; MacKinnon, 2000). Mediators are considered to be part of the process of "causality" in which a predictor variable influences a mediator and the mediator, in turn, influences the outcome variable. Mediators, similar to third variables, help provide explanation as to how an independent and dependent variable relate. For example, a strong negative relation between a child living in poverty and her school performance can be better explained by the degree to which the child's parents are involved in her schooling. When the mediator, "parents' involvement in schooling," is introduced into the equation and accounted for, the influence of poverty on school performance is reduced to a nonsignificant level.

Reduction to a zero relation (not frequently found in social sciences) when a mediator is introduced indicates total mediation. Reduction in the relation or a nonsignficant relation indicates partial mediation. Understanding intervening variables (mediators) as they explain the relation between an environmental or contextual factor and a youth development outcome, points to where intervention is likely to be most effective (Hansen, 1996). For example, if parental involvement in a child's school performance explains a negative relation between SES and academic achievement, creating a program that encourages low-income parents to increase their involvement in a child's schooling would be beneficial.

To test the hypothesized mediating role of volunteer support, we first assessed the following conditions for mediation using multiple regression analysis (MRA):

(a) the independent variable must be related to the mediator;

(b) the independent variable must be related to the dependent variable;

(c) the mediator must be related to the dependent variable; and

(d) the independent variable should become significantly smaller (partial mediation) (Baron \& Kenney, 1986). Measured variables were examined in combination using Baron and Kenny's (1986) method.

Initial MRA results showing partial mediation by volunteer support on the relation between organizational supports and youth life skills prompted further exploration and breakdown of variables using confirmatory factor analysis (CFA). Analytical methods included: exploratory factor analysis (EFA) of survey items; multiple regression analysis (MRA) for initial testing of mediation (SPSS Program); confirmatory factor analysis (CFA) through structural equation modeling (SEM) (AMOS software); and bivariate Pearson correlations among latent and manifest variables (SPSS).

\section{Measures}

The means, standard deviations, and reliabilities for all study variables are displayed in Table 2. For all measures, items were coded so that a high score indicates a high level of the characteristic being assessed. 
Environmental/Organizational Supports. Environmental/Organizational Supports were evaluated using ten scale items measuring youth perceptions of their sense of belonging in a supportive and inclusive environment. Measurement items included: "4-H clubs are supportive environments where I feel accepted" and "I feel like I fit in with my peers." Coefficient alpha for the scale was .92 indicating a high degree of internal consistency among measurement items.

Youth Engagement. Youth engagement, a latent construct, was indicated using three measured constructs: leadership roles, participation in 4-H events, and engagement in 4-H activities. Leadership roles included eight items that measured the various leadership roles held by survey participants in the youth organization. Roles included serving on club committees, club officer, County council officer, District/State council officer, youth-adult teaching teams, camp counselor, school committees, and community committees. Participation in 4-H events consisted of four items including county events, district events, state events, and national events. Participation in 4-H activities consisted of five items. These included: 4-H clubs, 4-H classroom or afterschool projects, fair 4-H events, 4-H day camps, and 4-H overnight camps.

To capture the context and educational value of participation, described by Lerner (2004), each activity, event and leadership role was weighted. For example, leadership roles were weighted from 1 indicating participation on club committees to 4 indicating participation in community service committees. Events were weighted from 1 indicating participation in local events to 4 indicating participation in national events. Activities were ranked in order from lower context and educational content to highest with $1=4-\mathrm{H}$ afterschool or classroom projects and $5=4-\mathrm{H}$ clubs. The scores from the three indicators were summed to create a single indicator for youth Engagement. Coefficient alpha for the scale was .80 indicating a high degree of internal consistency among measurement items.

Volunteer Support. Volunteer support, a latent construct was indicated using two measured variables: mentorship and club management. Coefficient alpha for the 8-item scale of mentorship was .94 indicating a high degree of internal consistency among measurement items. Mentorship scale items included: "My volunteer leader lets me know they have high expectations for me" and "My volunteer leader helps me with goal setting, decision-making and record keeping." Management was measured using ten items including: "My volunteer leader makes sure that 4-H activities are safe," "My volunteer leader manages conflict between youth" and "My volunteer leader makes sure that club members plan and lead 4-H meetings and activities." Internal consistency reliability was measured at .93 for management items.

Life Skills/Youth Outcomes. Life Skills/Youth Outcomes a latent construct was indicated by using three measured variables: mastery, self-responsibility and decision-making. Mastery was measured using 10 items. Coefficient alpha for the scale was .92 indicating a high degree of internal consistency among items. Items included as a result of 4-H, I am learning: "To organize my time, money, and other things used in my projects," "About my future career choices" and "To set and reach goals." Self-responsibility was measured using five items. Items included as a result of 4-H, I am learning: "To be responsible for myself," "To trust others and be trustworthy" and "I think through all of the good and bad results of different decisions before acting." Coefficient alpha for the scale was .84 indicating internal consistency among measurement items. Decision-making was measured using seven items. Items included as a result of 4-H: "I can make my own decisions" and "I can do things on my own." Coefficient alpha for the scale was .84 internal consistencies among measurement items. 
Control Variables. In addition to the latent constructs identified above, it is equally important to understand the role of gender differences in youth engagement and volunteer support. Participant gender was coded 1 for males and 2 for females. Given that it is not possible for youth to immediately participate in all leadership roles, events and activities, it was important to understand this relationship. Years in 4- $\mathrm{H}$ was measured by asking participants "how many years have you been enrolled in $4-\mathrm{H}$ ?"

Table 2

Measured items on Youth Engagement, Life skills, Organizational Support and Volunteer Support

\begin{tabular}{|l|r|r|r|}
\hline Measure & \multicolumn{1}{|c|}{$\boldsymbol{N}$} & \multicolumn{1}{c|}{ Mean } & \multicolumn{1}{c|}{ SD } \\
\hline Environmental/Organizational Supports & 624 & 4.30 & 0.73 \\
\hline Youth Engagement & & & \\
\hline Participation in 4-H Activities & 601 & 8.22 & 3.74 \\
\hline Participation in 4-H Events & 601 & 2.59 & 2.32 \\
\hline$\quad$ Leadership Roles & 601 & 4.12 & 5.55 \\
\hline Volunteer Support & & & \\
\hline Mentorship & 594 & 4.38 & 0.76 \\
\hline Management & 597 & 4.44 & 0.67 \\
\hline Life Skills & & & \\
\hline General Mastery & 620 & 4.02 & 0.77 \\
\hline Self Responsibility & 620 & 4.11 & 0.84 \\
\hline Decision Making & 617 & 4.35 & 0.71 \\
\hline
\end{tabular}

\section{Results \\ Correlations}

Correlation coefficients were computed among the variables in the structural equation model (SEM), including the latent variables youth engagement, volunteer support, and life skills, the measured variable of organizational support and control variables. The results of the analyses in Table 2 show that five of the possible six correlations between youth engagement, environmental/organizational support, volunteer support, and life skills were statistically significant at $\mathrm{p}<.05$.

Youth engagement was statistically significant and highly correlated to years in 4-H ( $r=.60$, $\mathrm{p}<.001)$ and to some degree life skills $(r=.20, \mathrm{p}<.05)$ and environmental/organizational support $(r=.18, p<.05)$. Volunteer support was statistically significant and highly associated with both life skills and environmental/organizational support $(r=.75, p<.001$ and $r=.78$, $\mathrm{p}<.001$, respectively) and to a lesser degree gender. Environmental/organizational support was statistically significant and highly correlated life skills $(r=.77, p<.001)$ and to a smaller degree gender $(r=.20, p<.05)$. Based upon these findings, separate SEM models were estimated for the study variables. 
Table 3

Correlations Among Variables in the Structural Equation Model

\begin{tabular}{|c|l|c|c|c|c|c|c|}
\hline \multicolumn{2}{|l|}{} & $\mathbf{1}$ & $\mathbf{2}$ & $\mathbf{3}$ & $\mathbf{4}$ & $\mathbf{5}$ & $\mathbf{6}$ \\
\hline 1. & Youth Engagement & 1.00 & & & & & \\
\hline 2. & Volunteer Support & .13 & 1.00 & & & & \\
\hline 3. & Life Skills & $.20^{*}$ & $.75^{* *}$ & 1.00 & & & \\
\hline 4. & Environmental/Organizational Support & $.18^{*}$ & $.78^{* *}$ & $.77^{* *}$ & 1.00 & & \\
\hline 5. & Gender & .09 & $.16^{*}$ & $.16^{*}$ & $.20^{*}$ & 1.00 & \\
\hline 6. & Years in 4-H & $.60^{* *}$ & .00 & .04 & .00 & .00 & 1.00 \\
\hline
\end{tabular}

\section{Relations Among Contextual Influences, Volunteer Support Systems and Life Skills}

Table 4 presents the regression results of the variables included in this study. Results show that volunteer support partially mediates the relation between supportive environments (settings for learning and representation of youth organization) and youth life skill outcomes.

First, correlation coefficients indicated that learning opportunities (.398) and environmental support (.422) positively with volunteer support providing support for hypothesis 1 and 2 . Next, correlation coefficients indicated that learning opportunities (.441) and environmental support (.450) positively with youth outcomes providing support for hypothesis 3 . Finally, correlation coefficients indicated that learning opportunities (.404) and environmental support (.352) are smaller when volunteer support is included as a variable providing support for the fourth hypothesis.

Table 4

Regression Mediator Model for Predictors on Life Skills

\begin{tabular}{|c|c|c|c|}
\hline & Beta & $\overline{R^{2}}$ & $p$ \\
\hline \multicolumn{4}{|c|}{$\begin{array}{l}\text { Step 1. Mediator, Volunteer Support, on Predictors: Environment/Organizational Support anc } \\
\text { Youth Engagement }\end{array}$} \\
\hline $\begin{array}{l}\text { Environmental/Organizational Support } \\
\text { Youth Engagement } \\
\text { Adjusted } R^{2} \\
\end{array}$ & \begin{tabular}{|l|}
.736 \\
-.050 \\
\end{tabular} & .461 & $\begin{array}{r}.000 \\
\mathrm{~ns} \\
.000 \\
\end{array}$ \\
\hline \multicolumn{4}{|c|}{$\begin{array}{l}\text { Step 2. Dependent Variable, Life Skills, on Predictors: Environmental/Organizational Support } \\
\text { and Youth Engagement }\end{array}$} \\
\hline $\begin{array}{l}\text { Environmental/Organizational Support } \\
\text { Youth Engagement } \\
\text { Adjusted } R^{2} \\
\end{array}$ & \begin{tabular}{|l|}
.745 \\
.048
\end{tabular} & .564 & $\begin{array}{r}.000 \\
\mathrm{~ns} \\
.000 \\
\end{array}$ \\
\hline \multicolumn{4}{|c|}{$\begin{array}{l}\text { Step 3. Dependent Variable, Life Skills, on Mediator, Volunteer Support, then Predictors: } \\
\text { Environmental/Organizational Support and Youth Engagement }\end{array}$} \\
\hline $\begin{array}{l}\text { Volunteer Support } \\
\text { Environmental/Organizational Support } \\
\text { Youth Engagement } \\
\quad \text { Adjusted } R^{2}\end{array}$ & $\begin{array}{l}.296 \\
.523 \\
.054\end{array}$ & .595 & $\begin{array}{r}.000 \\
.000 \\
\mathrm{~ns} \\
.000\end{array}$ \\
\hline
\end{tabular}




\section{SEM}

A structural equation model was used to evaluate the strength of direct relationships between: environmental/organizational support, youth engagement and life skills; and the indirect relationship that is mediated by volunteer support (Figure 1$)$. The independence model was readily rejected $\left(\chi^{2}=3567.72 \mathrm{p}<.000, \mathrm{df}=66\right)$. The mediation model provided a good fit for the data $\left(\chi^{2}=98.02 \mathrm{p}<.000, \mathrm{df}=37, \mathrm{RMSEA}=.05, \mathrm{Pc}=.41\right)$. All indicators had moderate to high loadings on their respective latent variables.




Regression analysis, shown in Table 4, indicated that volunteer support was predicted by environmental/organizational support (standardized coefficient $=.74, \mathrm{p}<.05$ ) and predicted life skills (standardized coefficient $=.30, \mathrm{p}<.05$ ). Volunteer support partially mediated the relationship between predictor and outcome measures, as indicated by a significant indirect path between environmental/organizational support and life skills (standardized coefficient for indirect effect $=.52, \mathrm{p}<.05$ ). It is noteworthy that volunteer support does not mediate the relationship between youth engagement and life skills (standardized coefficient $=-.05, p<.08$ ).

Principal components exploratory factor analysis (EFA) of items on the youth club survey (using varimax and oblimin rotations as alternatives to a non-rotated solution), produced three factors that explained the majority of inter-item variance: (1) volunteer support systems; (2) youth engagement in activities; and (3) environmental and organizational supports. A composite latent life skills outcome variable (CFA) reflected a variety of life skill types including: general mastery; decision-making skills; and self-responsibility.

The conceptual model was tested using SEM. In the model, environmental and organizational supports (youth program features) were both directly and indirectly related to youth life skills, whereas youth engagement in activities was only directly related to youth life skill outcomes.

Adult volunteer support was indicated by two major features: (1) mentorship - the one-on-one relationship of the adult volunteer with the youth; and (2) management - how volunteers managed clubs and worked with the group. The major finding was that volunteer support (and its two components of youth mentorship and club management) explained how organizational supports influenced youth life skill development.

\section{Discussion}

The study examined the mediating role of volunteer support in the relationship among youth engagement, supportive environments and youth outcomes in community-based clubs. Consistent with Boyce (1971), volunteers contribute to community clubs by carrying out many roles that both directly and indirectly affect youth. More than half of the variance in youth perceptions of adult volunteer support (53.5\%) is explained by the influence of environmental/organizational support and youth engagement. Volunteer support includes the relationships youth perceive having with their adult volunteers, volunteer disseminated information, volunteer delivered experiences, and how volunteers represent the organization and set the conditions for youth learning and participation in 4- $\mathrm{H}$.

Furthermore, volunteer support partly explains the role of youth organizational settings and learning opportunities provided within the organization as they are associated with life skills (youth outcomes) or competency development. Volunteer support is highly significant and explains nearly half the variance $(46.1 \%)$ in youth life skills. Volunteer support includes the relationships youth perceive having with their adult volunteers, volunteer disseminated information, volunteer delivered experiences, and how volunteers represent the organization and set the conditions for youth learning.

This model points to the potential role of adult volunteers in promoting positive youth development in community club environments. Volunteer support systems mediate or serve as a bridge between environmental influences and youth life skill outcomes. This is because volunteer support is related to each of the environmental influences and related to life skill outcomes. Volunteers may support the development of key youth life skills such as: decision- 
making skills (planning, organizing time and resources, and setting goals); self-responsibility skills; and general mastery skills (relationship building skills, community service, planning club activities in community, learning leadership).

Youth organizations as a whole potentially have great impact on youth through adult volunteers who represent their organization, create supportive, safe, and cognitively engaging environments. The next step is to determine what facets of adult volunteers most influence youth development. A multiple mediator model (cf., MacKinnon, 2000) would prove useful in examining those facets of volunteers which have the most influence on youth development. Once these areas are examined and explored, the emphasis of training and volunteer development can be tailored to develop these facets.

\section{Conclusion}

Ultimately, these findings offer support that volunteers help create environments of safety, challenging learning, and provide critical support meet youth needs and skill development. The research findings reveal no surprises. The best way to positively influence youth life skill development - as well as the community club environment and youth engagement in activities - is through supporting and training adult volunteers who work with youth.

Findings indicated that youth perceived that the volunteers who worked with them possessed adequate organizational knowledge of the youth program $(4-\mathrm{H})$, offered challenging learning opportunities for youth, created safe healthy environments for youth in clubs, and supported them through caring, encouraging relationships. The research here simply sums up a wellknown maxim that in youth programs "volunteers hold the key" to youth development. Also, youth development is represented by the life skills that youth possess - life skills that volunteers and youth program organizational structures and delivery systems help to develop.

The analyses performed using this youth community club evaluation survey provides supporting data from youth on three focus areas of youth organization program effectiveness, namely:

(1) creating high quality community-based learning environments for youth in clubs;

(2) creating caring adults support systems for youth; and

(3) developing life and career skills through subject-matter topics.

The data provided a useful means of conceptually organizing the influence of each of these three areas. Referring to the mediator model and also what is currently known about volunteer development in organizations, the support and training of adult volunteers may need to emphasize:

(1) sharing information on youth program opportunities at local, state and national levels with youth and adult volunteers;

(2) opportunities for professional growth in facilitating youth life skills as well as developing youth and adult subject matter expertise;

(3) organizational moral support and recognition of volunteers from national, regional and local levels;

(4) youth-adult partnership training in the community club environment; and

(5) education on fostering and maintaining developmentally appropriate, safe, and structured environments for youth. 


\section{Limitations}

The study also has some limitations. The nature of this study and its design did not collect information related to the roles of volunteers in community clubs or their level of involvement. Current research is examining the specific roles of volunteers in community clubs, levels of involvement in community clubs by volunteers and training in youth development. Additionally, the study did not collect information on lack of participation by youth. Specifically, data was not collected on why youth do not engage in leadership roles and high context, high educational value activities.

This was a cross-sectional, non-experimental design. Participants were not sampled in a stratified manner, rather on a voluntary basis. Data were not normally distributed and were negatively skewed. Future studies should involve a longitudinal design measuring life skill gains (or life skill levels over time) among participants, as well as examine multiple mediators using structural equation modeling (SEM). SEM provides fit indices and capacity to create latent constructs to approximate the conceptualized model of youth organization and volunteer input as each influence youth life skill outcomes. Moreover, when items indicating volunteer support alone (excluding other constructs) are entered into a factor analysis, a two factor solution emerges which conceptually consists of volunteers "managing youth behavior" and "offering mentoring support." Further examination that breaks down the volunteer support mediator into separate constructs, as well as inclusion of additional indicators of volunteer support are relevant to understanding "volunteer competencies" as they promote youth development. The development of staff and volunteer competencies is an integral part of youth programs. Knowing the skill areas that volunteers possess, as well as volunteer capacities that most strongly explain and promote youth life skill development, is useful information for youth programs. Key volunteer competencies - ones with greatest impact - ideally become the focus of staff and volunteer training development in youth programs.

\section{References}

Baron, R.M., \& Kenny, D.A. (1986). "The moderator-mediator variable distinction in social psychological research: Conceptual, strategic, and statistical considerations." Journal of Personality and Social Psychology, 51, 1173-1182.

Borden, L., \& Perkins, D. (2007). The roles volunteers can fill in community-wide efforts. The International Journal of Volunteer Administration, 24, 14-23.

Boyce, V.M. (1971). A systematic approach to leadership development. Paper presented at the USDA Extension Service, Pennsylvania and Missouri.

Blythe, D. (1992). Healthy communities; healthy youth. Minneapolis, MN: Search Institute.

Camino, L. (2000). Putting youth-adult partnerships to work for community change: Lessons from volunteers across the country. Community Youth Development Journal, 1(4), p.27-31.

Carnegie Corporation of New York. (1992). A matter of time: Risk and opportunity in the nonschool hours. New York, NY: Author. 
Christensen, P.N., Rothgerber, H., Wood, W., and Matz, D.C. (2004). Social norms and identity relevance: A Motivational Approach to Normative Behavior. Personality and Social Psychology Bulletin, 30(10).

Damon, W. (2004). "What is Positive Youth Development?" American Academy of Political \& Social Sciences, 591(13).

Dierking, L.D., \& Faulk, J.H. (2003). "Optimizing out-of-school time: The role of free-choice learning." New Directions for Youth Development, 97, 75-88.

DuBoise, D.L., Holloway, B.E., Valentine, J.C., \& Cooper, H. (2002). Effectiveness of mentoring programs for youth: A meta-analytic review. American Journal of Community Psychology, 30, 157-197.

DuBois, D.L., \& Karcher M.J. (Eds.). (2005). Handbook of youth mentoring. Thousand Oaks, CA: Sage Publications.

Eccles, J., \& Gootman, J.A. (2002). Community programs to promote youth development. Washington, D.C.: National Academy Press.

Freedman, M. (1992). The kindness of strangers: Reflections on the mentoring movement. Philadelphia: Public/Private Ventures.

Hansen, W.B. (1996). "Pilot test results comparing the All Stars Program with seventh grade D.A.R.E.: Program integrity and mediating variable analysis." Substance Use \& Misuse, 31, 1359-1377.

Kress, C. (2007, May). The Frameworks and Foundations of Youth Development Outreach. Preconference presented at the annual Children, Youth and Families at Risk (CYFAR) Conference. Chicago, IL.

Lerner, R.M. (2004). Liberty: Thriving and civic engagement among America's youth. Thousand Oaks, CA: Sage.

Lerner, R. (1995). America's youth in crisis. Thousand Oaks, CA: Sage.

MacKinnon, D.P. (2000). Contrasts in multiple mediator models. In J.S. Rose, L. Chassin, C.C. Presson, \& S.J. Sherman (Eds.), Multivariate Applications in Substance Use Research: New Methods for New Questions. Mahwah, NJ: Lawrence Erlbaum.

MacKinnon, D.P., \& Dwyer, J.H. (1993). Estimating mediated effects in prevention studies. Evaluation Review, 17, 144-158.

Rhodes, J.E. (2002). Stand by me: The risks and rewards of mentoring today's youth. Cambridge, MA: Harvard University Press.

Rodriguez, E., Hirschl T. A., Mead, J.P., \& Goggin, S.E. (1999). Understanding the difference 4-H clubs make in the lives of New York youth: How 4-H contributes to positive youth development. Retrieved December 10, 2002, from http://www.cce.cornell.edu/4h/Documents/final report.rtf 
Roth, J., Brooks-Gunn, J., Murray, L. \& Foster, W. (1998). Promoting healthy adolescents: Synthesis of youth development program evaluations. Journal of Research on Adolescence, 8 , 423-459.

Schorr, L. (1989). Within our reach: Breaking the cycle of disadvantage. New York, NY: Doubleday.

Search Institute. (2004). The Forty Developmental Assets for Adolescents. Minneapolis, MN.

Singletary, L., \& Smith, M. (2004). Nevada 4-H Statewide Impact Assessment. Reno: University of Nevada Cooperative Extension.

Stice, E., Presnell K., Gau, J., \& Shaw, H. (2007). Testing mediators of intervention effects in randomized controlled trials: An evaluation of two eating disorder prevention programs. Journal of Consulting and Clinical Psychology, 75, 20-32.

Zeldin, S., McDaniel, A., Topitzes, D., \& Lorens, M.B. (2001). Bringing young people to the table: Effects on adults and youth organizations. Community Youth Development Journal, 2(2) p. 20-27.

(C) Copyright of Journal of Youth Development $~$ Bridging Research and Practice. Content may not be copied or emailed to multiple sites or posted to a listserv without copyright holder's express written permission. However, users may print, download or email articles for individual use. 